\title{
Polymorphonuclear neutrophil function in systemic sclerosis
}

\author{
L CZIRJÁK, KATALIN DANKÓ,S SIPKA, MARGIT ZEHER, AND \\ Gy SZEGEDI
}

From the 3rd Department of Medicine, University Medical School of Debrecen, Debrecen, Hungary

SUMMARY In vitro functions of polymorphonuclear (PMN) neutrophils were studied in 20 patients with progressive systemic sclerosis (PSS). An increase in the basal chemiluminescent (CL) activity of peripheral blood PMNs was found, suggesting that these cells had beent preactivated in vivo. Patients with more extensive skin disease or signs of disease progressiog tended to have higher basal CL values. Active oxygen products during the respiratory burst mag increase the extent of inflammatory and fibrotic processes and could be involved in the endothelial injury in PSS. The stimulatory capacity of CL response was normal in our study. No alterations were found in the opsonised yeast phagocytic activity of granulocytes when compare with control values. The binding of erythrocyte-antibody particles was found also to be normal. depressed chemotactic activity of PMN cells against zymosan activated serum was also showị The cause of the decreased chemotaxis of PMNs remains to be elucidated.

Key words: chemiluminescence, chemotaxis.

Progressive systemic sclerosis (PSS) is characterised by fibrotic, degenerative, and inflammatory changes involving the skin and some internal organs. Although the cause of PSS is unknown, the microvascular involvement and abnormalities in the immune system are well characterised in patients with scleroderma. ${ }^{12}$

The mechanism(s) which lead to endothelial injury, inflammatory processes, and fibrosis are poorly understood in PSS. In these complex pathological events the polymorphonuclear neutrophils (PMNs) and their products may be involved in either endothelial injury or inflammatory and fibrotic processes. Spisani et al found normal yeast phagocytosis, spontaneous migration, and chemotactic activity of PMNs in nine patients with PSS. ${ }^{3}$

In our study we investigated the granulocyte functions of 20 patients with systemic sclerosis.

\section{Patients and methods}

PATIENTS

Twenty female patients with systemic sclerosis were investigated. Their mean age was 47.5 (SD 6.8)

Accepted for publication 22 September 1986.

Correspondence to Dr Czirják, 3rd Department of Medicine, University Medical School of Debrecen, 4004 Debrecen, Hungary. years (range 34-61). All patients fulfilled the preliminary diagnostic criteria for scleroderma Clinical data of the patients are given in Table Twelve patients received $30-50 \mathrm{mg}$ nifedipine daily D-Penicillamine was administered in six cases. prednisone in three. All drug administration was stopped 48 hours before blood collection. There. were no clinical signs of infection in patients wi PSS.

Controls were fifteen women matched by ageo

Table 1 Clinical profile of 20 patients with systemic sclerosis

Age (mean (SD), years)
Duration of disease (mean (SD), years)
Number of patients with:
'Proximal' scleroderma
Sclerodactyly
Joint symptoms
Raynaud's phenomenon
Lung involvement
Oesophageal dysfunction
Sicca syndrome
Myositis
Cardiac involvement
Renal manifestation
Calcinosis
Exposure to organic solvents

Number of patients with:

Sclerodactyly

Raynaud's phenomenon

13

18

18
19

Lung involvement

Oesophageal dysfunction

Myositis

Cardiac involvemen

Calcinosis

Exposure to organic solvents 
MEASUREMENT OF CHEMILUMINESCENCE The chemiluminescence (CL) of peripheral PMNs was investigated in heparinised whole blood, diluted fourfold with colourless, phenol red free Hanks's solution to a final volume of $1 \mathrm{ml}$. Each sample contained 10 units heparin. To $0.5 \mathrm{ml}$ of the diluted blood was added $0.5 \mathrm{mg} / 0.5 \mathrm{ml}$ of zymosan or $0.5 \mathrm{ml}$ of Hanks's solution (controls) at $37^{\circ} \mathrm{C}$ for $10 \mathrm{~min}$. Luminol at a concentration of $10^{-4} \mathrm{~mol} / \mathrm{l}$ was added to each sample. The chemiluminescence of cells was measured in glass vials by a Nuclear Chicago Isocap/300 liquid scintillation counter (Searle Industries, USA) in the off coincidence mode. ${ }^{56}$ The total number of photons in counts per minute (cpm) was measured five times at five-minute intervals, and the result was regarded as the characteristic value for each sample. The chemiluminescence values were related to the concentrations of PMNs in blood. The CL of blood unstimulated and stimulated by zymosan was determined and their rate was expressed by the stimulation index (SI).

$$
\mathrm{SI}=\mathrm{CL}(\mathrm{B}+\mathrm{Z}) / \mathrm{CL}(\mathrm{B})
$$

where $B=$ the basal value and $Z=$ the zymosan stimulated value.

MEASUREMENT OF YEAST PHAGOCYTOSIS BY GRANULOCYTES

PMNs from blood were isolated by sequential density centrifugation in Ficoll-Uromiro. Dextran (5\%) diluted in phosphate buffered saline (PBS) was used for the sedimentation of the granulocyteerythrocyte pellet. The time of incubation was $45 \mathrm{~min}$ at room temperature. After hypotonic lysis of residual erythrocytes the twice washed cells contained about $97 \%$ viable granulocytes. The neutrophils were suspended in PBS at $5 \times 10^{6}$ cells $/ \mathrm{ml}$.

A monolayer technique was used with cells adherent to a glass slide in a plastic collet fixed to glass by wax. Cells $\left(5 \times 10^{6}\right)$ were pipetted onto the slides, incubated at room temperature for $30 \mathrm{~min}$, and washed. Twenty five microlitres of bakers' yeast suspension (Saccharomyces cerevisiae) containing $5 \times 10^{6}$ particles in $0.5 \mathrm{ml}$ Parker's medium was added. After incubation at $37^{\circ} \mathrm{C}$ for $60 \mathrm{~min}$ in $5 \%$ $\mathrm{CO}_{2}$ and at $100 \%$ humidity the cells were washed and stained with $0.01 \%$ crystal violet or Wright's stain. Two hundred PMN cells in two parallel samples were evaluated, and the number of ingested particles was counted. The number of ingested yeast particles was divided by the total number of cells giving the phagocytic index (PI).

PHAGOCYTOSIS OF C 3 b COATED YEAST PARTICLES

The monolayer of granulocytes was incubated as described above at $37^{\circ} \mathrm{C}$ for $60 \mathrm{~min}$ with $25 \mu \mathrm{l}$ of $2 \times 10^{8} / \mathrm{ml}$ yeast particles opsonised with $1 \mathrm{ml}$ of human $\mathrm{AB}$ serum at $37^{\circ} \mathrm{C}$ for $60 \mathrm{~min}$ and washed. After incubation the cells wẹre washed, stained, and the PI was determined.

BIN DING OF ERYTHROCYTE-ANTIBODY (EA) CELLS BY GRANULOCYTES

The binding of sheep red blood cells (SRBCs) sensitised with a subagglutinating amount of IgG fraction isolated on Sephadex G-200 from a rabbit anti-SRBC serum (EA) was determined. The granulocytes were incubated with $0.2 \mathrm{ml}$ of $2 \%$ sensitised SRBCs in $0.3 \mathrm{ml}$ of Parker's medium at $37^{\circ} \mathrm{C}$ for $30 \mathrm{~min}$. After washing and staining the percentage of neutrophils binding or ingesting three or more SRBC particles (the granulocyte uptake of EA cells) was determined (EA \%).

\section{CHEMOTAXIS ASSAY}

A chemotactic test was performed by means of the micropore leading front assay. A modification of the Boyden chamber technique was used. ${ }^{7}$ Granulocytes $\left(0.5 \times 10^{6}\right)$ in $0.5 \mathrm{ml}$ medium with zymosan (Sigma, GFR) activated, complement derived chemotactic factor and $5 \mu \mathrm{m}$ pore size Millipore filter (Sartorius Membranfilter, GFR) were used in each sample. When the chambers were filled they were incubated at $37^{\circ} \mathrm{C}$ for $90 \mathrm{~min}$. A two cell leading front assay was used. The filters were stained with haematoxylin-eosin and evaluated microscopically by measuring the distance travelled by the two leading PMNs in five microscopic fields. The chemotactic test was carried out in triplicate.

The polyethylene glycol precipitation method ${ }^{\circ}$ was used to determine the immune complex levels of sera. The values for the samples were expressed as the actual percentage of the sample compared with the mean value for healthy controls.

\section{STATISTICAL ANALYSIS}

The mean values of the data and the standard deviation (SD) were calculated. Differences between groups were evaluated by a paired Student's $t$ test.

\section{Results}

Twenty female patients with PSS were investigated. The basal (unstimulated) chemiluminescence activity of phagocytes in diluted whole blood was found to be higher in the patients with PSS than in the controls $(p<0 \cdot 001$; Fig. 1$)$. In six patients with clinical signs of disease activity (recorded progression of skin or pulmonary symptoms, or both; active myositis) the basal chemiluminescence value was 


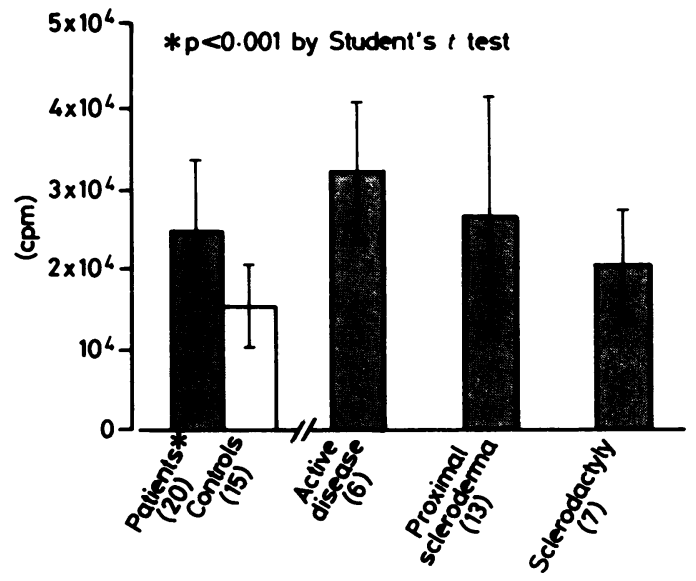

Fig. 1 The basal chemiluminescence of PMNs in patients with systemic sclerosis. The chemiluminescence values are expressed as the total number of photons in cpm measured five times at five-minute intervals. The number of cases are in parentheses.

greater than that for the other 14 patients, though the difference between the two groups was not statistically significant (Fig. 1). No differences were found when the eight patients with less than three years' disease duration were compared with the other 12 cases with a longer disease history. Patients with 'proximal' scleroderma tended to show higher basal chemiluminescence values than patients with acrosclerosis, but the difference between the two groups was not statistically significant (Fig. 1). The phagocytic functions of the five patients who had been previously exposed to organic solvents ${ }^{9}$ were indistinguishable from those of the other patients (data not shown).

The PMN chemiluminescence response of patients after stimulation by zymosan did not differ from that of the controls (154 (SD 48)\% of the basal chemiluminescence mean value $v 149(61) \%)$.

The yeast phagocytosis of granulocytes and the EA cell binding of PMNs were found to be normal. Similar results were obtained when the phagocytosis of $\mathrm{C} 3 \mathrm{~b}$ coated yeast particles was studied (Fig. 2).

In our study a reduced chemotactic activity of PMN neutrophils was found against zymosan activated particles (Fig. 3). No correlations with clinical symptoms were found.

The patients' sera showed a slightly increased immune complex level by the polyethylene glycol precipitation method (158 (SD 92)\% of the control values). There was no relation between immune complex levels and chemotactic, phagocytic functions of neutrophils (data not shown).

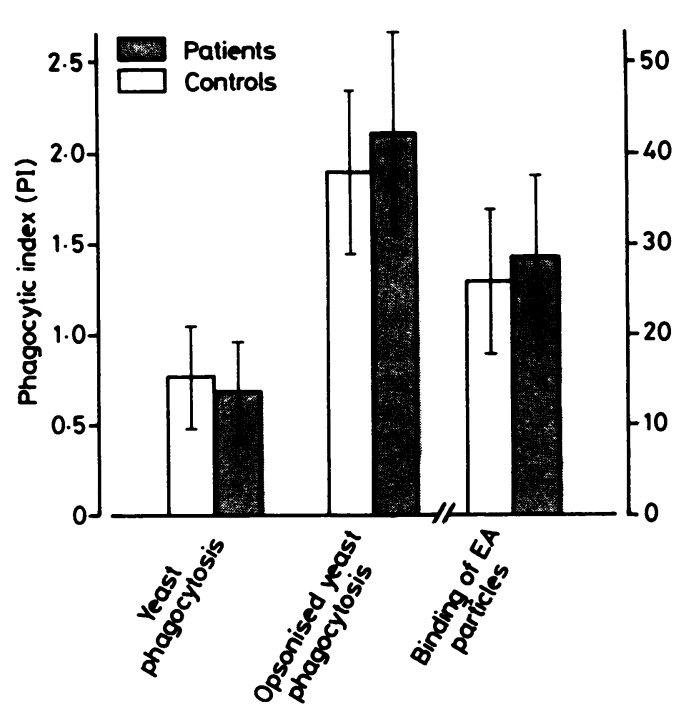

Fig. 2 Phagocytic function of PMNs in 20 patients with systemic sclerosis. The phagocytic index is expressed as the number of ingested yeast particles per total number of neutrophils. EA uptake is the percentage of neutrophils binding or ingesting three or more SRBC particles.

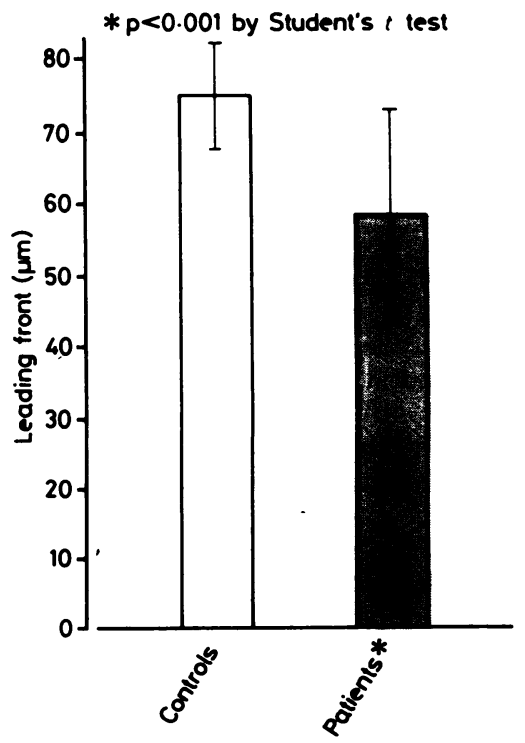

Fig. 3 Chemotaxis of PMNs against zymosan activated serum in 20 patients with PSS. The distance travelled by cells is expressed in micrometres $(\mu \mathrm{m})$ in the two cell leading front assay. 


\section{Discussion}

The complex pathological events which lead to vascular endothelial injury, inflammation, and fibrosis remain to be elucidated in patients with PSS. There are some data which suggest a possible role for PMN neutrophils in some of these pathological events. An increased ratio of neutrophils was found at the site of active fibrosis as the bronchoalveolar lavage studies showed in scleroderma. ${ }^{1(1-12}$

Measurement of the CL of phagocytic cells is a sensitive method for the characterisation of metabolic activity of phagocytes during phagocytosis. ${ }^{5}$ It is generally accepted that the CL measured in whole blood is derived almost completely from neutrophils. ${ }^{13}$ In our study a marked increase in the basal chemiluminescence activity of the blood phagocytes was found (Fig. 1), suggesting that the neutrophils from patients with PSS had been preactivated in vivo.

The cause of the increased basal neutrophil chemiluminescence value in patients with PSS remains to be elucidated. It is tempting to speculate that hypoxia near the microvessels could be one of the PMN activating factors. This hypothesis is supported by the fact that patients with more extensive skin disease or with signs of disease progression tended to have higher basal chemiluminescence values (Fig. 1). In these cases the microvascular injury and the hypoxia near the microvessels could be more pronounced. Recent evidence suggests that oxygen derived free radicals may be abundantly produced in ischaemic tissues. ${ }^{14}$

There is growing evidence that the intermediates of oxygen reduction products during the respiratory burst may increase the extent of inflammatory and fibrotic processes. Active oxygen products from normal stimulated granulocytes can damage the vascular endothelium in vitro. ${ }^{15}$ It has recently been suggested that endothelial cell cytotoxicity is mediated via a proteolytic mechanism involving the depression of antiprotease activities in scleroderma sera. ${ }^{16}$ One of the possibilities of functional defects in serum protease inhibitors is the direct damage from reactive oxygen species generated by phagocytosing neutrophils. ${ }^{17}$ Endothelial cells can also be destroyed indirectly through the lipid peroxidation as a result of neutrophil activation. ${ }^{18} 19$ Oxygen radicals can mediate endothelial cell damage by complement stimulated granulocytes. ${ }^{20}$ PMN cells incubated with soluble immune complexes or IgG aggregates generate a dose dependent chemiluminescence response, indicating a membrane activation and production of oxygen radicals. ${ }^{21}$ In our study the basal chemiluminescence value of granulocytes was not significantly influenced by patients' sera. Platelet or mast cell exposure to oxidants or free radicals may also influence the subsequent inflammatory and haemostatic reactions. ${ }^{22} 23$

There are few data about the behaviour of granulocytes in patients with PSS. Phagocytotoxic autoantibodies were found in scleroderma sera. ${ }^{24}$ An increased eosinophil chemotactic activity was shown in $30 \%$ of patients with PSS. ${ }^{25}$ Spisani et al found a normal in vitro yeast phagocytic activity in nine patients with PSS. ${ }^{3}$ The random migration of granulocytes was also normal. Our results are consistent with these findings considering the normal rate of yeast phagocytosis by PMN cells. This method is less sensitive than the chemiluminescence assay.

In our study the uptake of EA cells was found to be normal in PSS. In contrast with Spisani's findings, ${ }^{3}$ we found a reduced chemotactic activity of PMNs. The discrepancy could be attributed to the discrepancies in methods and demographic differences or to the relatively small number of patients investigated. The cause of the depressed chemotaxis of PMNs in PSS is unknown and further investigations are needed. Granulocytotoxins, other serum factors, and chemotaxis inhibitors may influence the chemotaxis of neutrophils. ${ }^{2426}$ The effect of lymphokines or the impaired leucocyte adherence may also cause a decreased chemotactic response of neutrophils. ${ }^{27}$ Either reduced number or down regulation of membrane chemoattractant receptors may also be involved in the depressed chemotactic activity of PMNs in PSS.

Normal zymosan phagocytosis was found in patients with systemic lupus erythematosus, but findings are inconsistent in patients with rheumatoid arthritis. ${ }^{28-30}$ In patients with malignancies the basal chemiluminescence activity was raised. ${ }^{31}$

Alterations in the functions of PMN cells could, in a complex way, influence the vascular, immunological, and fibrotic processes in patients with PSS.

\section{References}

1 Jayson M I V. Systemic sclerosis: a collagen or microvascular disorder? $\mathrm{Br} J$ Med 1984; 288: 1855-7.

2 Sternberg E M. Pathogenesis of scleroderma: the interrelationship of the immune and vascular hypothesis. Surv Immunol Res 1985: 4: 69-80.

3 Spisani S. Dovigo L. Colamussi V. Leukocyte migration and phagocytosis in progressive systemic sclerosis. Scand J Rheumatol 1981; 10: 299-300.

4 Subcommittee for scleroderma criteria. Preliminary criteria for the classification of systemic sclerosis (scleroderma). Arthritis Rheum 1980; 23: 581-90.

5 Ernst M. Heberer M. Fischer $\mathbf{H}$. Chemiluminescence measurement of immune cells. A tool in immunobiology and clinical research. J Clin Chem Clin Biochem 1983; 21: 555-600.

6 Sipka S, Ábel Gy, Csongor J, Chihara G, Fachet J. Effect of Lentinan on the chemiluminescence produced by human 
neutrophils and the murine macrophage cell line C4MO. Int $J$ Immunopharmacol 1985: 7: 747-51.

7 Lukács K. Kávai M. Bányai A. et al. Effect of immunc complexes from SLE patients on human monocvte locomotion and Fc receptor function. Ann Rheum Dis 1984: 43: 729-33.

8 Riha I. Haskova V. Kaslik J. Maicrova M. Stransky J. Use of polyethylene glycol for immune complex detection in human sera. Mol Immunol 1979: 16: 489-93.

9 Czirják L. Dankó K. Schlammadinger J, Surányi P. Tamási L. Szegedi Gy. Progressive systemic sclerosis occurring in patients exposed to chemicals. Int J Dermatol (in press).

10 Kallenberg C G M. Jansen H M. Elema J D. The T H. Steroidresponsive interstitial pulmonary disease in systemic sclerosis. Chest 1984: 86: +89-92.

11 Rossi G A. Bitterman P B. Rennard S I. Ferrans V J. Crystal $R$ G. Evidence for chronic inflammation as a component of the interstitial lung disease associated with progressive systemic . sclerosis. Am Rev Respir Dis 1985: 131: 612-7.

12 Silver R M. Metcalf J F. Stanley J H. LeRoy E C. Interstitial lung disease in scleroderma. Analysis by bronchoalveolar lavage. Arthritis Rheum 1984: 27: 1254-62.

13 Johnston R B, Lehmeyer J E. Guthric L A. Generation of superoxide anion and chemiluminescence by human monocytes during phagocytosis and on contact with surface-bound immunoglobulin. J Exp Med 1976: 143: 1551-6.

$14 \mathrm{McC}$ ord $\mathrm{J} \mathrm{M}$. Oxygen-derived free radicals in postischemic tissue injury. $N$ Engl $J$ Med 1985: 312: 159-63.

15 Weiss S J. Young J. LeBuglio A F. Slivka A. Role of hydrogen peroxide in neutrophil-mediated destruction of cultured endothelial cells. J Clin Invest 1981; 68: 714-21.

16 Kahaleh M B. LeRoy E. Endothelial injury in scleroderma. A protease mechanism. J Lab (lin Med 1981: 101: 553-60.

17 Carp H. Janoff A. In vitro suppression of serum elastase inhibiting capacity by reactive oxygen species generated by phagocytosing polymorphonuclear leukocytes. J Clin Invest 1979: 63: 793-7.

18 Blake D R, Winyard P, Scott D G I. Brailsford S, Blann A. Lunec $J$. Endothelial cell cytotoxicity in inflammatory vascular disease-the possible role of oxidised lipoproteins. Ann Rheum Dis 1985; 44: 176-82.

19 Catchart M. Morel D W. Chisolm G M. Monocytes and neutrophils oxidize low density lipoprotein making it cytotoxic. J Leukocyte Biol 1985; 38: 341-50.
20) Sacks T. Moldow C F. (raddock P R. Bowers T K. Jacob H P Oxygen radicals mediate endothelial cell damage by comple? ment stimulated granulocrtes. J Clin Invest 1978: 61: 1161-

21 Starkenbaum G D. Stevens L. Henry ('. Gavin S E. Stimulation of human neutrophil chemiluminescence by soluble immug complexes and antibodies to neutrophils. J Lab ( lin Med 198 98: $281-6$.

22 Handin R I. Karabin R. Boxer J. Enhancement of platele function by superoxide anion. J (lin Invest 1977: 59: 959-6?

23 Ohmuri H. Komonja K. Azuma A. Korozumi S. Hashimoto है? Xanthine-oxidase induced histamine release from isolated rat peritoneal mast cells. Involvement of hydrogen peroxid? Biochem Pharmacol 1979: 28: 333-9.

24 Pruzanski W. Lee P. Willshire A. Gladman D. Keystone E Lymphocytotoxic and phagocytotoxic activity in progressio systemic sclerosis. J Rheumatol 1983: 10: 55-60).

25 Wasserman S I. Seibold J R. Medsger T A Jr. Rodnim G P. Serum cosinophilotactic activity in cosinophilic fasciit? Arthritis Rheum 1982: 25: 1352-8.

26 Walker J R. Smith J H. An inhibitor of leucocvte movement क्ष the plasma of patients with rheumatoid arthritis. Ann Rheun Dis 1980: 39: 563-5.

27 Keller H U. Barandun S. Kistler P. Ploem J S. Locomotion at adhesion of neutrophil granulocytes. Kxp (ell Res 1974): 122 351-62.

28 Nagasawa K. Nakamura M. Jimi S. et al. Phagocytosi connected oxygen consumption by peripheral leukocytes frof patients with systemic lupus erythematosus. Acta Haemaky (Basel) 1982; 68: 84-8.

29 Hallgren R. Hakansson L. Venge P. Kinetic studies o phagocytosis. I. The serum independent particle uptake PMN from patients with rheumatoid arthritis and systemic lupd erythematosus. Arthritis Rheum 1978: 21: 107-13.

30) Breedveld F C. Barselaar M T van den. Leijh P C. Cats Furth $\mathrm{R}$ van. Phagocytosis and intracellular killing by polymof phonuclear cells from patients with rheumatoid arthritis a Felty`s syndrome. Arthritis Rheum 1985: 28: 395-4(1)4.

31 Braun D P. Harris J E. Maximovich S. Marder R. Lint T E Chemiluminescence of peripheral blood mononuclear cells solid tumor cancer paticnts. Cancer Immunol Immunother 1984: 12: $31-7$. 